\title{
ДОСЛІДЖЕННЯ КОНТАКТНОЇ ВЗАЄМОДІЇ ЦИЛІНДРИЧНИХ ТІЛ НА ПОХИЛОМУ ТРАНСПОРТЕРІ У ФАРМАЦЕВТИЧНІЙ ТЕХНОЛОГІЇ
}

Н. О. Кравець

Тернопільський державний медичний університет імені І.Я.Горбачевського

\begin{abstract}
Досліджено ударну взаємодію тіл обертання на транспортних лініях розливу ліків при рухові по нахилених конвеєрах. Встановлені і обгрунтовані аналітичні залежності для знаходження максимальних значень зближення центрів мас і критичних зусиль при центральному ударі на різних швидкостях руху конвеєра і типорозміру склотари. Показано, що характерний час встановлення контактних деформацій за фрормулою статичної пружності (задача Герца) менший типового часу взаємодії склотари, що підтверджує коректність використання статичної теорії.
\end{abstract}

Ключові слова: транспортні лінії розливу ліків, контактна взаємодія.

\section{ДОСЛІДЖЕННЯ КОНТАКТНОЇ ВЗАЄМОДІЇ ЦИЛІНДРИЧНИХ ТІЛ НА ПОХИЛОМУ ТРАНСПОРТЕРІ У ФАРМАЦЕВТИЧНІЙ ТЕХНОЛОГІЇ}

Н. О. Кравець

Тернопільський державний медичний університет імені І.Я.Горбачевського

\begin{abstract}
Исследовано ударное взаимодействие тел вращения на транспортных линиях разлива лекарств при движении по наклонных конвеерах. Установленные и обоснованные аналитические зависимости для нахождения максимальных значений сближения центров масс и критических усилий при центральном ударе на разных скоростях движения контейнера и типоразмера склотары. Показано, характерное время установления контактных деформаций по формуле статической упругости (задача Герца) меньше типичного времени взаимодействия склотары, что подтверждает корректность использования статической теории.
\end{abstract}

Ключевые слова: транспортные линии разлива лекарств, контактное взаимодействие.

\section{STUDY OF THE CONTACT INTERACTION OF CYLINDRICAL BODIES ON THE INCLINED CONVEYER IN PHARMACEUTICAL TECHNOLOGY}

N. O. Kravets

\author{
Ternopil State Medical University by I. Ya. Horbachevsky
}

\begin{abstract}
There was studied the percussive interaction of bodies rotation on transport lines of medicaments' bottling on inclined conveyers. There were determined and substantiated the analytical dependences for finding out the maximum meanings of raprochement of different speeds of conveyer's motion and glass packages type and size. There was shown that the typical time of determination of contact deformations by the statistic elasticity (Herts' sum) is less than the typical time of interaction of glass packages, that confirms the usage correctness of statistic theory.
\end{abstract}

Key words: transport lines of drugs bottling, the contact interaction.

Вступ. Ударна взаємодія в механічних системах має ряд загальних рис: кінематичні особливості - короткочасність удару, в результаті якого відбуваються різкі зміни швидкостей точок системи; динамічні особливості - виникнення, а потім зникнення великих ударних сил. Як правило, сили, що виникають при ударі, невідомі і підлягають визначенню в процесі рішення конкретної задачі [1].
Основна частина. Твердження про миттєвість співудару, що пропонується Ньютоном за спрощеною схемою, не дозволяє визначити сили взаємодії між тілами, які співударяються. Формально значення цих сил отримуються нескінченно великими [1]. Тому ударна взаємодія ототожнюється із наближенням тіл і визначається за відомою формулою статичної пружності (задача Герца). Тобто, якщо початковий дотик

(C) Н. О. Кравець 
тіл здійснюється в одній точці (або по дотичній), а відстань між поверхнями тіл поблизу цієї точки (прямої) описується рівнянням другого порядку, то сила ударної взаємодії [1]:

$$
P=\beta \cdot x^{3 / 2}
$$

де $\beta$ - стала, що залежить від властивостей матеріалу тіл взаємодії; $x$ - величина зближення тіл, що контактують.

Деформація стискання тіл, які обмежені поверхнями обертання, може бути перевірена експериментом. Така деформація ототожнюється з наближенням тіл і розв'язується в часткових варіантах при застосуванні теорії контактних напружень [2]. Однак, в частковому випадку, коли початковий контакт двох тіл відбувається по прямій лінії, знаходження значення деформації стискання отримує логарифмічну залежність - наближення прямує до безмежності, що свідчить про недостатність теорії Герца [3, 4].

Як доповнення до теорії Герца, формулу для визначення наближення або повної пружної деформації отримав Динник А. Н. [2], розглядаючи стискання елементарного циліндричного диска двома діаметрально протилежними зусиллями. Ця формула з нашими позначеннями отримає вигляд:

$x=-\frac{4 \cdot\left(1-\mu^{2}\right)}{\pi \cdot E} \cdot q \cdot\left[\ln \frac{2 \cdot R}{b}+\frac{1}{3}\right]$,

де $x$ - величина зближення циліндрів, що контактують, або повна діаметральна деформація стискання; $\beta$ - півширина смуги контакту; $\gamma$ - погонне навантаження в контактах циліндра; $R$ - радіус циліндричного диска.
Формула (2) була уточнена Ковальським Б. С. [5]:

$x=-\frac{4 \cdot\left(1-\mu^{2}\right)}{\pi \cdot E} \cdot q \cdot\left[\ln \frac{2 \cdot R}{b}+0.407\right]$.

Формули (2) і (3) застосовуються для визначення зближення контактуючих циліндричних тіл. I хоча очевидним є факт відмінності між деформацією стискання тіл обертання і наближенням, у відомих роботах підтвердження цього не знайдено $[2,3,6]$.

На однопотокових лініях розливу ліків у фармацевтичній промисловості відбувається постійне призупинення руху флаконів (на час наповнення), що викликає миттєве співударяння, яке може призвести до биття тари. Тому, необхідно здійснювати правильний вибір кінематичних параметрів ланок лінії, особливо на перевантажувальних ділянках, які, як правило, розміщені під кутом до горизонталі [7].

Задачею нашого дослідження є встановлення взаємозв'язку між швидкостями переміщення флаконів і силою контактної взаємодії скляної тари різної місткості при транспортуванні на конвеєрі по похилій площині. Рух тари на конве єрі відбувається з малими швидкостями i, відповідно, швидкості співударяння повинні бути невеликими. Тобто, можна застосувати теорію Герца, де напруження, що виникають в зоні контакту, не перевищують границю пружності.

Розглядався випадок динамічної контактної взаємодії скляної тари при центральному ударі, тобто знаходилось максимальне значення деформації стискання циліндричних тіл (максимальне наближення), що взаємодіють в діаметральній осьовій площині (рис.1).

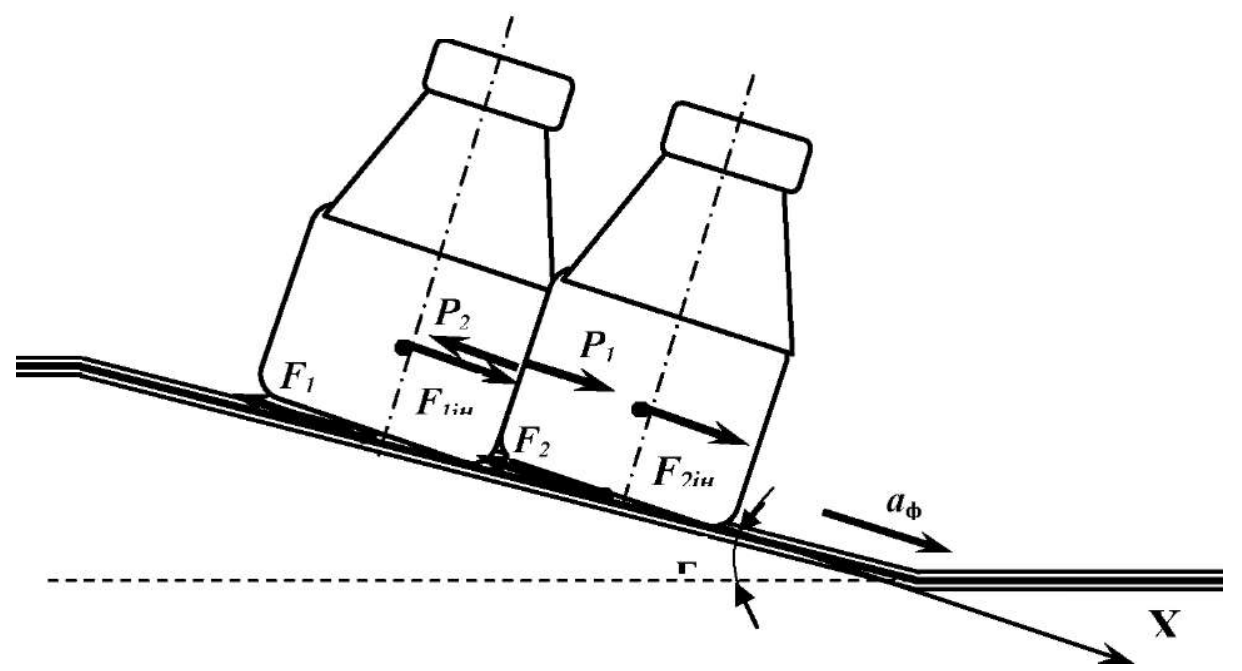

Puc.1. Розрахункова схема ударної взаємодії тіл обертання.

При складанні аналітичної моделі процесу введемо наступні припущення: флакони, що транспортуються, мають правильну циліндричну форму; діаметри цилін- дричних частин, їх маси, є величини постійні; перила на конвеєрі паралельні; флакони здійснюють поступальний рух; силами тертя флаконів об перила нехтуємо. 
Переміщення центрів мас тіл $\mathrm{x}_{1}$ та х 2 відраховується від стану, що відповідає моменту першого контакту, $\mathrm{i}$ початок відліку суміщається з цим моментом. В цьому випадку рівняння руху двох тіл, згідно з вибраною системою координат (рис. 1), отримує вигляд:

$$
\begin{aligned}
& m \cdot \ddot{x}_{1}-\vec{F}_{1}+\vec{F}_{1 і н}-P_{1}(x)=0 \\
& m \cdot \ddot{x}_{2}-\vec{F}_{2}+\vec{F}_{i н}-P_{2}(x)=0
\end{aligned}
$$$$
\text { де } \vec{F}_{1}, \vec{F}_{2},\left(\vec{F}_{1}=\vec{F}_{2}=\mu \cdot m \cdot g\right) \text { - сили тертя пер- }
$$

шого і другого флаконів на площині в початковий момент контакту, відповідно; $\vec{F}_{1 i н}=\vec{F}_{2 i н}=m \cdot g \cdot \sin (\gamma)$ - сили інерції руху першого і другого флаконів в момент призупинення руху, відповідно; $\boldsymbol{m}$ - маса флаконів (однакова); $P_{7}(x), P_{2}(x)$ - сили ударної взаємодії першого і другого флаконів, які рівні між собою; $\gamma$ · кут нахилу площини; $\ddot{x}_{1}, \ddot{x}_{2}-$ лінійні прискорення першого і другого флаконів, відповідно.

Віднявши рівняння в системі (4) отримуємо зближення центрів мас флаконів в процесі співударяння:

$\left(\ddot{x}_{1}-\ddot{x}_{2}\right) \cdot M=-P(x)$,

де $M$ - приведена маса системи $\left(M=\frac{m_{1} \cdot m_{2}}{m_{1}+m_{2}}\right)$.

Враховуючи те, що маси флаконів рівні, рівняння (5) отримає вигляд:

$\ddot{x}=-\frac{2 \cdot P(x)}{m}$.

Провівши інтегрування рівняння (6) отримуємо:

$$
\frac{1}{2} \cdot \dot{x}^{2}=-\frac{2}{m} \int_{0}^{x} P(x) d x+C \text {. }
$$

Для знаходження постійної $C$ задамо початкові умови: в момент початкового зіткнення $(\mathrm{t}=0)$ перший флакон співударяється з другим з лінійною швидкістю руху конвеєра $\vartheta_{0}$ (сили інерції флаконів зрівноважуються із силами тертя флаконів при рухові на похилій площині), тобто $C=\vartheta_{0}^{2} / 2$, і отримуємо:

$$
\dot{x}^{2}-\vartheta_{0}^{2}=-\frac{4}{m} \int_{0}^{x} P(x) d x
$$

Враховуючи, що в момент найбільшого зближення відносна швидкість руху $\dot{x}=0$, знаходимо найбільше зближення тіл $X_{\max }$ і найбільшу ударну силу, тобто $\mathrm{P}_{\max }$, використавши формулу (1), отримуємо:

$\vartheta_{0}^{2}=\frac{4}{m} \int_{0}^{x_{\max }}\left(\beta \cdot x^{3 / 2}\right) d x$

звідки:

$x_{\max }=\left[\frac{5 \cdot m}{8 \cdot \beta} \cdot \vartheta_{0}^{2}\right]^{2 / 5}$,

а найбільша ударна сила:

$P_{\max }=\beta^{2 / 5} \cdot\left(\frac{5}{8} \cdot m\right)^{3 / 5} \cdot \vartheta_{0}^{6 / 5}$

Час досягнення максимального зближення знаходимо провівши інтегрування рівняння (7):

$$
\frac{d x}{d t}=\sqrt{\vartheta_{0}^{2}-\frac{4}{m} \cdot \int_{0}^{x} P(x) d x},
$$

звідки:

$$
t=\int_{0}^{x_{\max }} \frac{d x}{\sqrt{\vartheta_{0}^{2}-\frac{4}{m} \cdot \int_{0}^{x} P(x) d x}}
$$

Використовуючи вираз (1) отримуємо кінцеву формулу:

$$
t=\int_{0}^{x_{\max }} \frac{d x}{\sqrt{\vartheta_{0}^{2}-\frac{8 \cdot \beta}{5 \cdot m} \cdot x^{\frac{5}{2}}}}
$$

Для проведення експериментальних досліджень і аналізу ударної взаємодії необхідно провести оцінку сталої $\beta$. яка залежить від динамічних властивостей матеріалу. У фармацевтичній, як і в харчовій промисловості, властивості динамічної міцності скла розглядають в залежності від умов навантаження, розмірів і форми склотари і впливу зовнішнього середовища. [7]. Оскільки на лініях розливу до наповнення флаконів медикаментами транспортування відбувається при звичайних температурних режимах, бу- 
демо характеризувати критичну міцність за модулем зсувної деформації при мікроруйнуванні матеріалу $\mathrm{G}$, який зв 'язаний із модулем пружності $E$ i коефiцієнтом деформації (коефіцієнтом Пуансона) т співвідношенням $G=E / 2 \cdot(1+\mu)$, тобто значення коефіцієнта $\beta$ визначаємо за формулою:

$$
\beta=\frac{E}{2 \cdot(l+\mu)} \cdot \sqrt{\frac{R_{1} \cdot R_{2}}{R_{1}+R_{2}}},
$$

де $\mathrm{R}_{1}, \mathrm{R}_{2}$ - радіуси циліндричних поверхонь, які співударяються, або, врахувавши, що радіуси флаконів однакові, отримуємо:

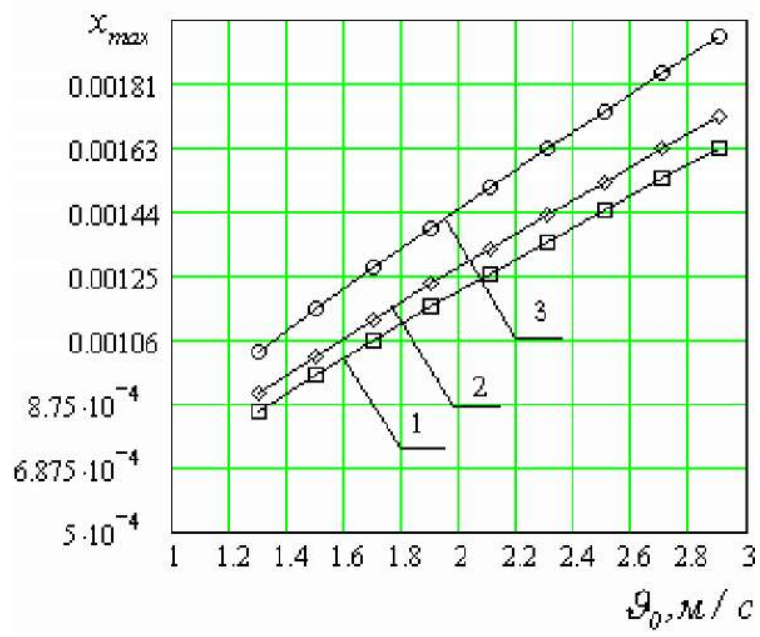

$\beta=\frac{E}{2 \cdot(1+\mu)} \cdot R \cdot \sqrt{\frac{1}{2 \cdot R}}$.

Розрахунок критичних значень зближення центрів мас, ударної сили і часу ударної взаємодії за встановленими аналітичними залежностями проводився при типових швидкостях руху конвеєра $\left(\vartheta_{0}=1,3 \div 3 \mathcal{M} / c\right)$ коли присутня ймовірність биття тари [7] при різних типорозмірах флаконів за вхідними даними: $E=50 \cdot 10^{6} \Pi a, \mu=0,23$. Отримані графічні залежності представлені на рисунку $2 a, \sigma$.

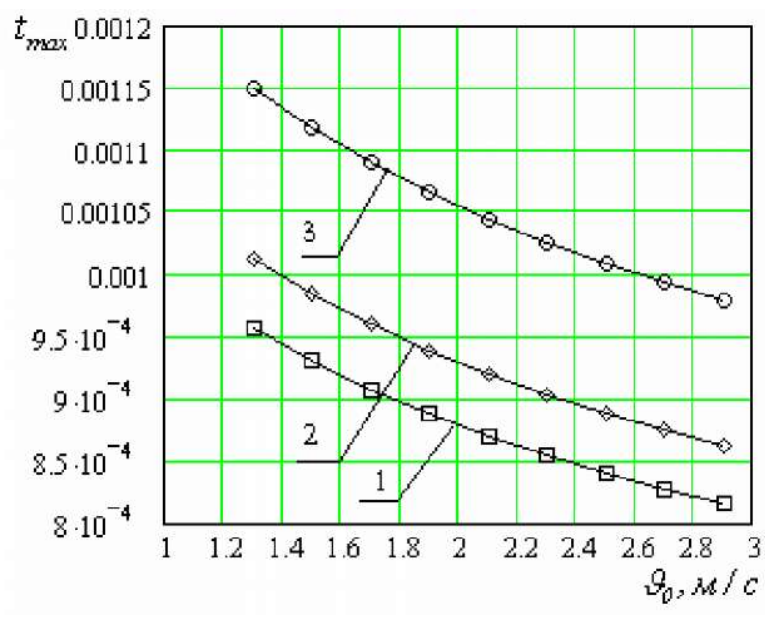

Puc. 2. Залежність максимального зближення (а) та часу досягнення максимального зближення (б) від швидкості руху конвеєра для флаконів:

$$
\begin{gathered}
1-R=0,016 м, m=0,0367 \kappa 2 ; 2-R=0,019_{м, m}=0,046 \kappa 2 ; \\
3-R=0,021 \mu, m=0,0664 \kappa 2 .
\end{gathered}
$$

Розглянемо контакт двох флаконів. При прикладанні сили $P$ у статичному випадку, зближення за рахунок деформації буде визначатися формулою (1). Але, при миттєвому прикладанні сили $P$ одного флакона до іншого, значення максимального зближення $X_{\max }$ буде досягнуто не відразу, а в результаті перехідного процесу динамічної зміни $x$ в часі, причому, процес співударяння буде мати затухаючий характер. Рівняння, яке описує перехідний процес $X(t)$, може бути отримано при розгляді балансу сил взаємодії (прикладеної сили $P$ i пружним відгуком $G \cdot R \cdot \sqrt{1 /(2 \cdot R)})$

$$
\begin{aligned}
& m \cdot \ddot{x}+\alpha \cdot \dot{x}+G \cdot R \cdot \sqrt{1 /(2 \cdot R)}=P \\
& x(0)=0, \dot{x}(0)=0, \\
& \alpha-\text { коефіцієнт затухання. }
\end{aligned}
$$

Графік численнного роз'язку рівняння (12) наведено на рисунку 3. При розрахунку використовували такі параметри: $m=0,0367 \kappa 2, \quad R=0.016 \mu$, $P=45,383 \mathrm{H}, \beta=1,818 \cdot 10^{6}$. Із розв'язку випливає, що характерний час деформації має порядок $t \approx 3_{\text {мкс }}$ (така оцінка отримана і при обрахунку за статичною формулою (10)). 


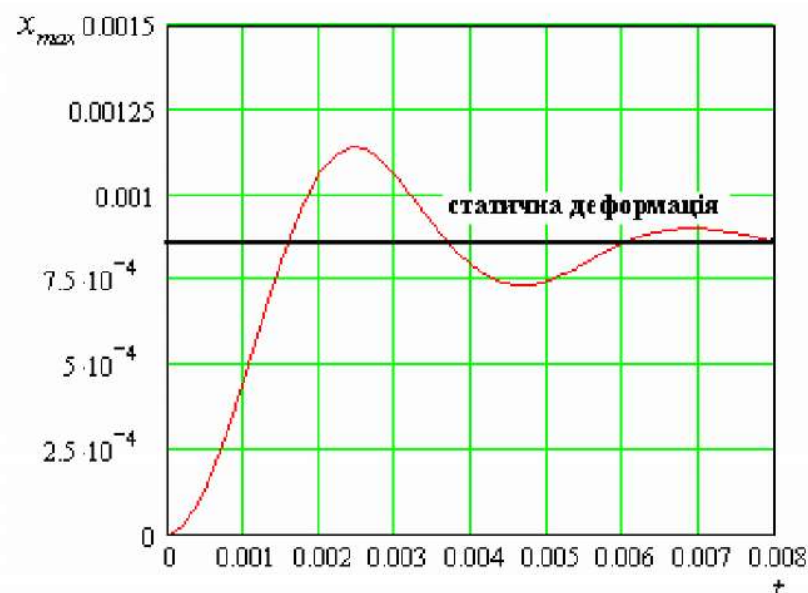

Puc. 3. Графічна залежність динамічної зміни максимального зближення в часі.

Висновок. Характерний час встановлення контактної деформації і значення максимального зближення тіл обертання при аналізі перехідного процесу є більшими, ніж при обрахунку за формулами статич-

\section{Література}

1. Пановко Я. Г. Основы прикладной теории колебаний и удара / Я. Г. Пановко. - Л. : Политехника, 1990. - 272 с.

2. Динник А. Н. Удар и сжатие упругих тел / А. Н. Динник. - К. : Изд-во АН УССР, 1952. - Т. 1. - 151 с.

3. Беляев Н. М. Труды по теории упругости и пластичности / Н. М. Беляев . - М. : Гостехиздат, 1957. - 632 с.

4. Fopple L. New ableitung der Hartzschen harteformelein fur die walse / L. Fopple//Zeitschrift fur Angewandte mathematik und mechanik. - 165. - S. 170. - 1920.

5. Ковальский Б. С. К вопросу о напряжениях при местном ної теорії, тобто реально контактні напруження вже закінчаться. Це говорить про коректність використання при аналізі поставлених завдань формул статичної теорії контактних деформацій.

сжатии / Б. С. Ковальський // Научные записки Харьковского авиационного института. - 1990. - Т. 2(5). - С. 107-116. 6. Римар О. М. Деформація стискання тіл обертання / О. М. Римар, I. С. Керницький, Б. С. Штангрет // Подъемнотранспортная техника. - Дніпропетровськ. - № 1-2. - 2002. - C. 60-65.

7. Погрузочно-разгрузочные и транспортные операции на линиях разлива пищевых продуктов / А. И. Соколенко, М. И. Юхно, А. И. Ковалёв [и др.] - М. : Агропромиздат, 1986. $-175 \mathrm{c}$. 